\title{
Thoracic surgery without intubation: Revisiting the challenges of a previous century
}

\author{
Nirmal K. Veeramachaneni, MD
}

\footnotetext{
From the Department of Cardiovascular and Thoracic Surgery, University of Kansas Health System, Kansas City, Kan.

Disclosures: Author has nothing to disclose with regard to commercial support.

Received for publication Jan 16, 2018; accepted for publication Jan 29, 2018; available ahead of print March 9 , 2018.

Address for reprints: Nirmal K. Veeramachaneni, MD, Department of Cardiovascular and Thoracic Surgery, University of Kansas Health System, 4000 Cambridge St, Kansas City, KS 66160 (E-mail: nveeramachaneni@ kumc.edu).

J Thorac Cardiovasc Surg 2018;155:2755-6

$0022-5223 / \$ 36.00$

Copyright (c) 2018 by The American Association for Thoracic Surgery

https://doi.org/10.1016/j.jtcvs.2018.01.053
}

Minimally invasive tracheal and carinal resection with a nonintubated, spontaneous ventilation technique represents a tour de force in surgery. To appreciate the ingenuity presented by Jiang and colleagues ${ }^{1}$ in this issue of the Journal in their article, "Thoracoscopic Surgery for Tracheal and Carinal Resection and Reconstruction Under Spontaneous Ventilation," it is helpful to provide historical context. A century ago, chest surgery was deemed a near impossibility because of the problem of an open pneumothorax. To address this problem, Sauerbruch developed a system in which the patient's torso and the surgical team would be placed inside a negative pressure chamber. This technique fell to the wayside when Samuel Meltzer (first president of The American Association for Thoracic Surgery) described a method of intratracheal insufflation anesthesia in 1908. Meltzer's work was revolutionary and forms the basis of modern thoracic surgery and anesthesia. A century later, surgeons have revisited the concept of nonintubated thoracic surgery.

In the past 2 decades, there have been several reports on the application of minimally invasive techniques in the nonintubated patient. Katlic ${ }^{2}$ recently reported on more than 500 patients undergoing thoracic surgery procedures for lung biopsy, pleural disease resection, and other procedures with local anesthetic and IV sedation only. Others have described nonintubated chest surgery for thymectomy and lung resection, ${ }^{3}$ multiport videoassisted thoracoscopic surgical resection of lung nodules, ${ }^{4}$ resection of lung nodule with single-port video-assisted thoracoscopic surgery, ${ }^{5}$ and single-port anatomic lung resection ${ }^{6}$ with a variety of analgesia strategies including epidural catheters, local blocks, and nonparalytic intravenous anesthesia, with a laryngeal mask to support the airway.

In evaluating the literature, it is important to distinguish the airway management technique from the degree of anesthesia provided to the patient. The depth of sedation and analgesia is a continuum. According to the American

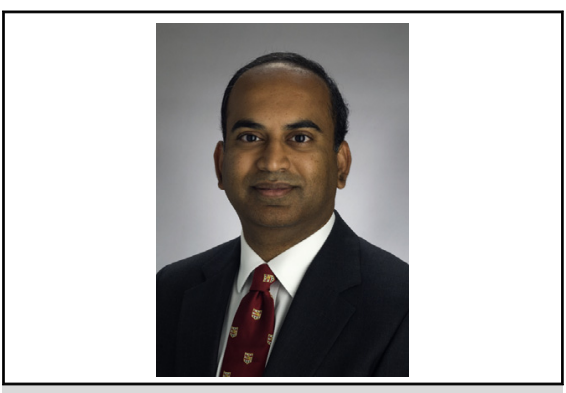

Nirmal K. Veeramachaneni, MD

Central Message

Complex thoracic surgery with spontaneous ventilation and without the use of an endotracheal tube is possible. This surgical and anesthetic technique expands the armamentarium for the surgeon.

See Article page 2746.

Society of Anesthesiologists, to be considered moderate "conscious sedation," a patient must be responsive enough to provide purposeful response to verbal or tactile stimulation (not just a pain reflex), without need for airway intervention to maintain adequate spontaneous ventilation, and without need for intervention to maintain cardiovascular function. The anesthetic technique used by Jiang and colleagues, ${ }^{1}$ and described in other recent publications on anatomic resection without intubation, is best defined as deep sedation or general anesthesia without the use of an endotracheal tube. In the current article on tracheal resection of Jiang and colleagues, ${ }^{1}$ the carefully selected patients with low body mass index and low American Society of Anesthesiologists class are treated with infusions of sufentanil and propofol targeted to bispectral index monitoring levels typical for general anesthesia. ${ }^{7}$ A laryngeal mask is used to maintain the airway, and local anesthetic is infiltrated to lessen the cough response. An expert anesthesiologist monitors the patient for complications of hypercapnia and hypoxemia and is prepared to intubate the patient in the lateral decubitus position.

The reported advantages of this airway management technique are shorter recovery and decreased physiologic stress. $^{8}$ There are now convincing data on the feasibility of a nonintubated video-assisted thoracoscopic surgical strategy for both minor and major thoracic surgery procedures, presenting a new opportunity for the thoracic 
surgeon to find innovative solutions to an age-old problem.

\section{References}

1. Jiang L, Liu J, Gonzalez-Rivas D, Shargall Y, Kolb M, Shao M, et al. Thoracoscopic surgery for tracheal and carinal resection and reconstruction under spontaneous ventilation. J Thorac Cardiovasc Surg. 2018;155:2746-54.

2. Katlic MR. Five hundred seventy-six cases of video-assisted thoracic surgery using local anesthesia and sedation: lessons learned. J Am Coll Surg. 2018;226: 58-63.

3. Al-Abdullatief M, Wahood A, Al-Shirawi N, Arabi Y, Wahba M, Al-Jumah M, et al. Awake anaesthesia for major thoracic surgical procedures: an observational study. Eur J Cardiothorac Surg. 2007;32:346-50.
4. Pompeo E, Mineo D, Rogliani P, Sabato AF, Mineo TC. Feasibility and results of awake thoracoscopic resection of solitary pulmonary nodules. Ann Thorac Surg. 2004; 78:1761-8.

5. Rocco G, Romano V, Accardo R, Tempesta A, La Manna C, La Rocca A, et al. Awake single-access (uniportal) video-assisted thoracoscopic surgery for peripheral pulmonary nodules in a complete ambulatory setting. Ann Thorac Surg. 2010;89:1625-7.

6. Gonzalez-Rivas D, Aymerich H, Bonome C, Fieira E. From open operations to nonintubated uniportal video-assisted thoracoscopic lobectomy: minimizing the trauma to the patient. Ann Thorac Surg. 2015;100:2003-5.

7. Avidan MS, Zhang L, Burnside BA, Finkel KJ, Searleman AC, Selvidge JA, et al. Anesthesia awareness and the bispectral index. N Engl J Med. 2008;358: 1097-108.

8. Mineo TC, Tacconi F. From "awake" to "monitored anesthesia care" thoracic surgery: a 15 year evolution. Thorac Cancer. 2014;5:1-13. 